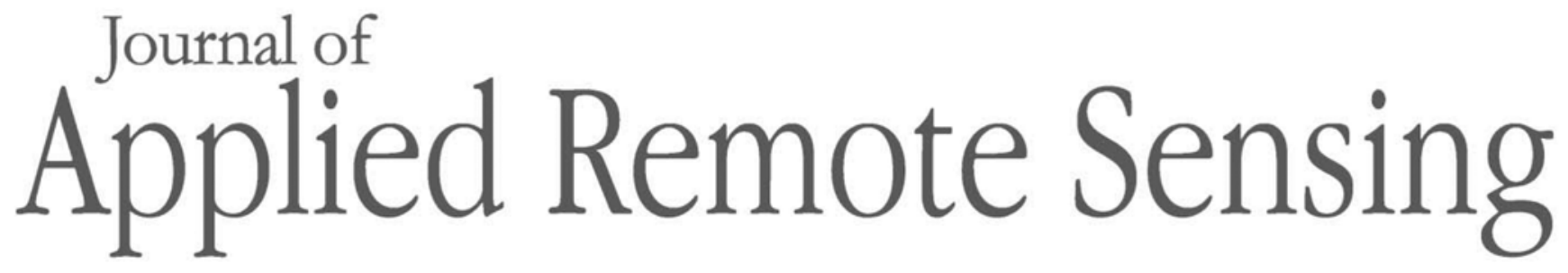

RemoteSensing.SPIEDigitalLibrary.org

\title{
Space-based vegetation health for wheat yield modeling and prediction in Australia
}

Felix Kogan

Wei Guo

Wenze Yang

Harlan Shannon 


\title{
Space-based vegetation health for wheat yield modeling and prediction in Australia
}

\author{
Felix Kogan, ${ }^{\mathrm{a}, *}$ Wei Guo, ${ }^{\mathrm{b}}$ Wenze Yang, ${ }^{\mathrm{b}}$ and Harlan Shannon ${ }^{\mathrm{c}}$ \\ ${ }^{a}$ National Oceanic and Atmospheric Administration, National Environmental Satellite Data and \\ Information Services, Center for Satellite Applications and Research, Maryland, United States \\ ${ }^{b}$ I.M. System Group Inc., Rockville, Maryland, United States \\ ${ }^{\mathrm{c}}$ World Agricultural Outlook Board, Office of Chief Economist, \\ United States Department of Agriculture, Washington, DC, United States
}

\begin{abstract}
An early warning of crop losses in response to weather fluctuations helps farmers, governments, traders, and policy makers better monitor global food supply and demand and identifies nations in need of aid. This paper discusses the utility of vegetation health $(\mathrm{VH})$ indices, derived from the advance very high-resolution radiometer (AVHRR) and visible infrared imaging radiometer suite (VIIRS), as a proxy for modeling Australian wheat from the National Oceanic and Atmospheric Administration (NOAA) operational afternoon polar-orbiting satellites. These models are used to assess wheat production and to provide an early warning of drought-related losses. The NOAA AVHRR- and VIIRS-based VH indices were used to model wheat yield in Australia. A strong correlation $(\geq 0.7)$ between wheat yield and VH indices was found during the critical reproductive stage of development (enhanced crops sensitivity to weather), which starts 2 to 3 weeks before and ends 2 to 3 weeks after wheat heading. The results of modeling and independent testing proved that the VH indices (especially those estimating thermal and health conditions) are a good proxy providing 1 to 2 months before harvest yield prediction (with $3 \%$ to $6 \%$ error). With the new generation of NOAA-20 operational polar-orbiting satellites, launched in November 2017, the VH method will be improved considerably both in an advanced crop/pasture prediction, spatial resolution, and accuracy. (c) The Authors. Published by SPIE under a Creative Commons Attribution 3.0 Unported License. Distribution or reproduction of this work in whole or in part requires full attribution of the original publication, including its DOI. [DOI: 10.1117/1.JRS.12.026002]
\end{abstract}

Keywords: satellite-based yield modeling; vegetation health method; crop losses prediction; moisture and thermal vegetation stress.

Paper 180007 received Jan. 4, 2018; accepted for publication Mar. 15, 2018; published online Apr. 12, 2018.

\section{Introduction}

Among the major world grain producing countries, Australia is a modest contributor (1.3\%) to total global production, ranking ninth with slightly over 32 million tons of grain collected on average annually during 1993 to $2013 .{ }^{1}$ However, Australia is among the world's largest grain exporting nations (USA, Russia, European Union, and Canada), ranking fifth in wheat exported annually (contributing $4 \%$ to $8 \%$ to global grain in trade) since the $1980 \mathrm{~s}^{2,3}$ Most of the Australian wheat that is sold overseas is produced in western and southern Australia. The major Australian export markets are in the Asian and Middle East regions, which include Indonesia, Japan, South Korea, Malaysia, Vietnam, and Sudan. ${ }^{4}$ Considering the substantial global demand for grain, wheat in Australia is a significant contributor to the nation's economy. Grain and oilseed crops produce about 35 to 45 million tons per annum from an area of slightly more than 20 million hectares, with an annual gross production value of around $\$ 9$ to 13 billion. ${ }^{4}$ Among grains, wheat is the principal crop grown in Australia and is typically sown in April to

*Address all correspondence to: Felix Kogan, E-mail: Felix.Kogan@noaa.gov 

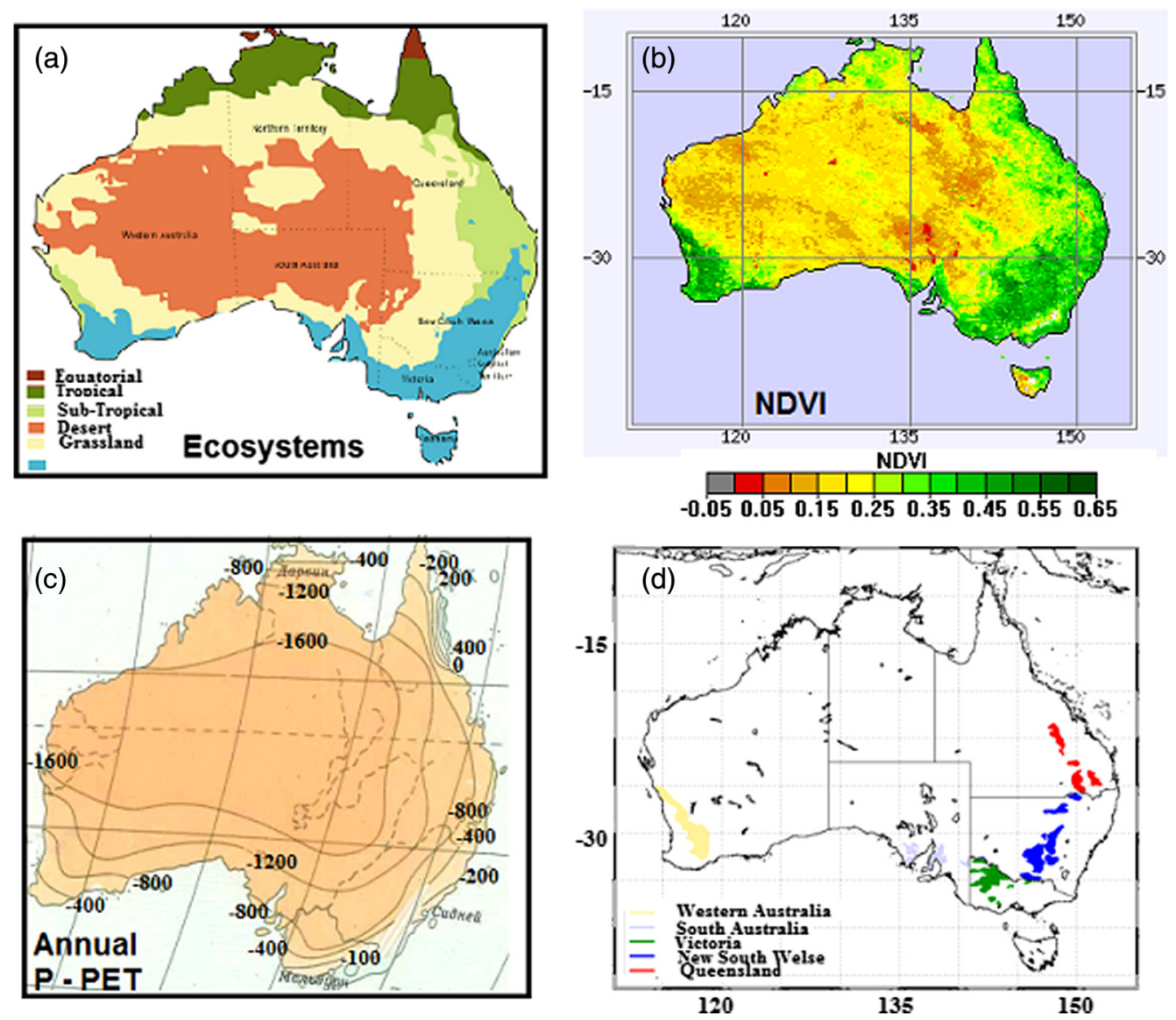

Fig. 1 Environmental resources and wheat in Australia: (a) ecosystems, (b) midseason (June 21, 2016) NDVI, (c) shortage of water [difference between annual precipitation $(P)$ and potential evapotranspiration (PET)], and (d) wheat growing area.

May and harvested in October to November. The main producing states in the country are Western Australia, New South Wales, South Australia, Victoria, and Queensland. Wheat grown for domestic consumption and feedstock is predominately produced on Australia's east coast. Therefore, an advanced knowledge about the amount of wheat collected in a particular year is very important not only for the estimation of domestic grain availability and use but also for projections of global trade and also for accurate assessment of supply/demand and consequently global food security.

Of the nearly 800 million hectares of land in Australia, only $10 \%$ is suitable for crops and pastures. The majority of the land is desert, semidesert, and some grasslands [Fig. 1(a)]. In general, the soils in Australia have low fertility, especially compared with the excellent soils of European Russia (south) and USA's prairies. Australia's climate is mostly arid, such that any shortage in rainfall combined with hot weather puts considerable strain on water resources, and thus agriculture. ${ }^{3,4}$ Annual precipitation in the two biggest ecosystems (desert and grassland) is greater than in the other world's big deserts (for example, Sahara) and grassland (China) areas, accounting for 50 to $250 \mathrm{~mm}$ in desert and 250 to $500 \mathrm{~mm}$ in grassland. ${ }^{5}$ Therefore, these areas have some vegetation and the normalized difference vegetation index (NDVI) is quite elevated [0.10 to 0.25 , Fig. 1(b)], compared to similar ecosystems in the other world areas. ${ }^{6}$ However, precipitation in nearly $90 \%$ of Australia is much below potential evapotranspiration [the difference is -1200 to $-1800 \mathrm{~mm}$, Fig. 1(c)] due to extremely high temperatures during the growing season, ${ }^{5,7}$ which limits agricultural activities.

Examination of climate and weather characteristics of Australia reveals that the wheat growing areas still have a negative balance [-300 to $-600 \mathrm{~mm}$, Fig. 1(c)] between annual precipitation and potential evapotranspiration..$^{5}$ Moreover, during the warmest months temperatures are relatively high $\left(24^{\circ} \mathrm{C}\right.$ to $\left.26^{\circ} \mathrm{C}\right)$ and up to 10 days during the growing season air temperatures can 
be $40^{\circ} \mathrm{C}$ or higher, increasing stress on winter wheat. Therefore, wheat production can be significantly impacted by precipitation and temperature extremes. For example, in drought years up to $55 \%$ of wheat production might be lost. ${ }^{3}$ The weather station network in Australia provides data that are useful for estimating weather impacts on wheat production, but the number of stations and their density are limited compared with data sets that can be obtained via remote sensing [Fig. 1(d)]. Therefore, high-resolution operational satellite data, used before in other grain producing countries, were tested in Australia for modeling wheat yield and assessment of model-based yield prediction in advance of harvest. These results are discussed in the paper.

\section{Data}

This study employs satellite and in situ data. In situ data were presented by mean Australia wheat production $[P$, tons $(\mathrm{t})]$ and area $\left[A\right.$, hectares (ha)] from 1961 to $2014 .{ }^{1}$ The principals of data aggregation were the following: $P$ and $A$ were collected from the reports of farms growing wheat at the end of each agricultural year and aggregated to the Australia total country level. Country mean yield $(Y, \mathrm{t} / \mathrm{ha})$ was calculated as a ratio of the country's $P / A$. Satellite data were collected from the National Oceanic and Atmospheric Administration (NOAA) global vegetation health (VH) data product from 1981 to $2014 .{ }^{6,8}$ The VH product was developed from the 4-km² Advanced Very High Resolution Radiometer (AVHRR) flying on NOAA operational polarorbiting satellites since 1980 and currently from the Visible Infrared Imaging Radiometer Suite (VIIRS) flying on the new generation of Suomi National Polar-Orbiting Partnership (S-NPP) satellite since 2012. Spatial data resolution was $4 \mathrm{~km}^{2}$ and temporal-7-day composite sampled from each of the 7-day data. ${ }^{8-10}$ The original AVHRR data were solar radiation in the visible (VIS, 0.58 to $0.68 \mu \mathrm{m}$ ), near-infrared (NIR, 0.725 to $1.0 \mu \mathrm{m}$ ), and infrared (10.3 to $11.3 \mu \mathrm{m})$ spectral bands. The VIIRS similar data ${ }^{11}$ were VIS $(0.600$ to $0.680 \mu \mathrm{m})$, NIR ( 0.846 to $0.885 \mu \mathrm{m}$ ), and IR (10.0 to $12.4 \mu \mathrm{m}$ ), which are different than AVHRR and need to be adjusted in order to use them together. Pre- and postlaunch calibrated VIS and NIR counts were converted to reflectance for each pixel and week $^{8}$ and used to calculate the NDVI $=$ $(\mathrm{NIR}-\mathrm{VIS}) *(\mathrm{VIS}+\mathrm{NIR})^{-1}$ the infrared counts were converted to brightness temperature (BT). NDVI and BT data were composited over a 7-day period, processed to remove shortand long-term noise, special climatology was calculated, and the data were converted to three vegetation health indices (VHI). ${ }^{9,10,12,13}$

\section{Methodology}

\subsection{Satellite Data}

The advances in the application of operational satellites in the recent 35-year have proved that observed radiances are an excellent tool for monitoring the environmental impacts on agriculture. The initial attempts in the application of remote sensing data for yield modeling and assessment has started from the late 1970s using Landsat/MSS and SPOT/VGT along with NOAA/ AVHRR data. ${ }^{14,15}$ Most of research used the satellite-derived NDVI ${ }^{16}$ for yield modeling and assessment. The results were quite promising since NDVI correlated with total vegetation dry matter, primary production, and yields. ${ }^{14,17-19}$ NDVI application has expanded with the launch of NOAA-7 afternoon operational polar-orbiting satellite with AVHRR sensor on board. Modeling was initially focused on grain yield in Africa since the continent suffered from drought and has food security problems in many countries. ${ }^{20-22}$ With an establishment of NOAA operational polar-orbiting satellites as a reliable source of data for vegetation monitoring, NDVI-based yield assessment was applied to other areas (North America, Asia, and Europe) and was combined with in situ data such as rainfall and some indices, for example, $z$-index. ${ }^{18,22-29}$ Such assessments were typically used by the United Nations' Food and Agriculture Organization, Famine Early Warning System, United States Agency for International Development, European Commission's MARS project, and others. ${ }^{25}$ In the early 1980's, new VH methodology was introduced, permitting, in addition to NDVI, to use radiative temperature (BT) and also to use that portion of NDVI and BT, which are controlled 
by weather only. ${ }^{9,10}$ The VH method has introduced VHI derived from the processed NDVI and infrared radiance converted to BT. NDVI is based on a combination of reflectance in VIS and NIR channels. Reflectance in the VIS part of solar spectrum is strongly controlled by chlorophyll and water contents, and NIR depends on vegetation biomass and vigor and, through them, on water content. ${ }^{26}$ Following these biophysical considerations, NDVI was accepted as an indicator of moisture content in vegetation; ${ }^{9} 10,14,17$ BT is a characteristic of vegetation thermal conditions. ${ }^{9,10}$ Additionally, such data-aided drought detection and monitoring in USA, China, Greece, Mongolia, Brazil, Poland, Argentina, Morocco, Kazakhstan, Mexico, and other countries. ${ }^{12,13,30-38}$ In the strategy of yield modeling was to: (a) derive weather-impact component in crop yield; (b) derive VHI; (c) correlate weather-related components of yield and VHI; (d) assess if the time of the strongest correlation coincides with wheat critical period in Australia; (e) select predictors; (f) construct models; (g) predict wheat yield; and (h) validate the results in an independent test.

\subsection{Yield Data}

Since most Australia areas have a very dry climate with deserted type of ecosystems [Figs. 1(a)1(c)], wheat is growing in a very limited area of the eastern and southern Australia [Fig. 1(d)]. One of the most important problems to match wheat area with the corresponding VHI is to calculate wheat area mask in order to collect satellite data for that area. The wheat belt mask was delineated using Australian Bureau of Statistics 2010 to 2011 Agricultural Census data. ${ }^{28}$ Statistical area level 2 (SA2) wheat production data were downloaded for the entire country. Because the size of each SA2 region differs, the wheat production data were divided by the area of each SA2 region to remove sampling size bias. The normalized data were then ranked from the most productive to the least productive SA2 regions. The major wheat-producing areas were defined as the most productive SA2 regions within the country, which combined account for $85 \%$ of national wheat production. This area coincides with "general purpose wheat (GPW)" type, which is equivalent to the area of hard wheat. ${ }^{39}$ The mask shown in Fig. 1(d) was used to digitize satellite data inside this mask. The delineated GPW mask (AWB 2018) was digitized (using specific software) in order to collect all $4 \mathrm{~km}^{2}$ pixels inside this area, which was used to calculate mean VHI values for each year in this research.

Over at least a 20-year period, crop yields often experience a statistically significant longterm trend (mostly upward) because of technological improvements in crop cultivation (breeding, mechanization, fertilizers, pest/diseases control, etc.). This trend can be approximated by a polynomial (either linear or nonlinear depending on the longevity of yield series and climate impacts), which illustrates this change over time. Annual fluctuations in crop yields around the trend are often a result of weather variations during the growing season from year to year. In years when the weather is favorable for crop development, yields often exceed the trend. In contrast, when unfavorable weather occurs, yields often dip below the trend. Following these considerations, yield time series were divided into two components: technology-related trend and yield deviation from the technological trend. ${ }^{40,41}$ The first one characterizes longterm yield tendency associated with technology change and the second characterizes variation of yield around the trend due to year-to-year weather fluctuations. The second component is normally expressed as a ratio of actual to trend-estimated yield.

During 1981 to 2014, wheat yields ( $Y$ ) in Australia experienced an upward trend [Fig. 2(a)] due to improvements in the applied agricultural technology. This trend $(Y t)$ was approximated linearly as a function of year number by the following equation:

$$
Y t=0.1198 * \text { Year }-222.84 \text {. }
$$

This equation approximates technology-based yield level provided that weather is nearnormal (close to many-year mean). Following this equation, technology provided wheat yield increase from $1.4 \mathrm{t} /$ ha in 1981 to nearly $1.8 \mathrm{t} /$ ha in 2014 , adding nearly $22 \%$ during 25 years. In spite of such a strong increase, weather-related variations around the trend, shown in Fig. 2(b), are very large indicating strong weather contribution to yield variations from year-to-year. During the most unfavorable weather years, especially those associated with droughts, wheat 

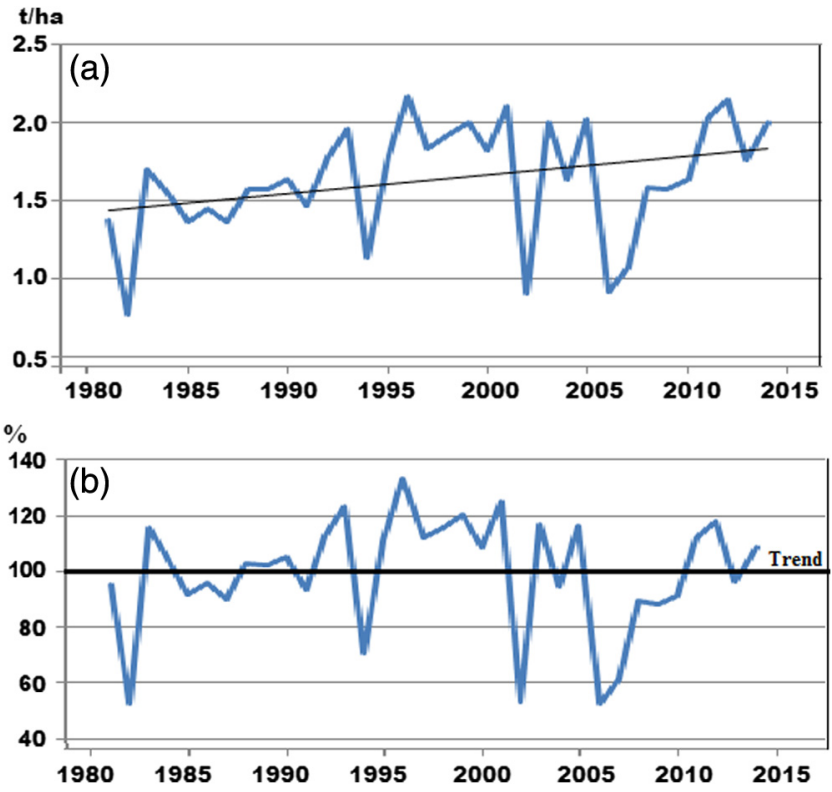

Fig. 2 Hard wheat yields in Australia during 1981 to 2014: (a) collected annually ( $Y$ ) and linear trend [Yt, Eq. (1)] and (b) deviation from trend [d $Y \%$, Eq. (2)].

yield might be reduced up to $40 \%$ to $50 \%$ below the trend (for example, 1982 and 2001). These deviations $(\mathrm{d} Y)$ were approximated $\mathrm{as}^{40}$

$$
\mathrm{d} Y i=100 *[(Y i-Y T i) / Y T i] .
$$

There is currently a concern that yield increase is associated not only with agricultural technology improvement but also with climate changes. ${ }^{29}$ We investigated NDVI, BT, and rainfall several decade time series from wheat area of Australia. ${ }^{42,39}$ Figure 3 presents these results, showing that neither of these parameters has changed since the early 1980s. Moreover,
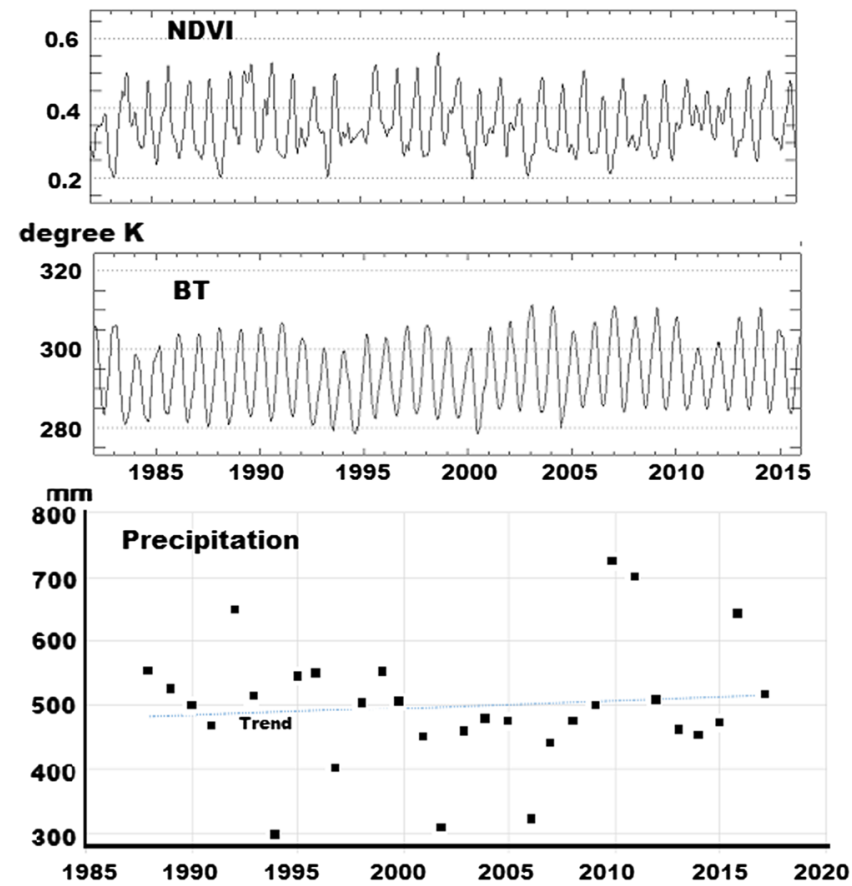

Fig. 3 Weekly NDVI, BT during 1982 to 2017 and annual precipitation (1987 to 2017) in wheat area of Australia. 
Australian Bureau of Meteorology ${ }^{27}$ calculated temperature anomaly for the entire Australia during the recent 115 years, showing that the temperature is warming up since 1910. During the period of our investigation (from the early 1980s), temperature anomaly increased around $0.3^{\circ} \mathrm{C}$ (from $0.4^{\circ} \mathrm{C}$ to $0.5^{\circ} \mathrm{C}$ to $0.7^{\circ} \mathrm{C}$ to $0.8^{\circ} \mathrm{C}$ ). Desert, occupying $80 \%$ of Australia, provides considerable contribution to this trend. Our BT data in wheat are of Australia do not show any trend (Fig. 3). Therefore, for the data of our investigation, it is possible to consider that wheat increase was not associated with moisture (NDVI) and thermal (BT) climate changes.

\subsection{Vegetation Health Indices}

The principle for constructing VHI stems from the properties of green vegetation to reflect and emit solar radiation. If vegetation is healthy it reflects little radiation in the VIS part of the solar spectrum (due to a higher amount of chlorophyll, which absorbs more incident radiation), much in the NIR part (due to higher water content and specificity of scattering the light by leaf internal tissues), and emits less in the IR (because the transpiring canopy is cooler). As a result, calculated NDVI becomes large and the IR-derived BT small. Oppositely, for unhealthy vegetation, the NDVI becomes smaller (reduced chlorophyll and water amount) and the BT larger (vegetation surface becomes hotter following reduced transpiration). The VH algorithm described in Kogan ${ }^{9}$ includes three multilayer steps: (1) data processing, which includes radiance retrieval, pre- and postlaunch calibration, calculation of VIS and NIR reflectance and IR emission, calculating top of the atmosphere (TOA) NDVI and BT [TOA was warranted since noise removal in step (2) eliminated most of atmospheric contamination impacts on NDVI and BT values], adjusting NDVI and BT between AVHRR and VIIRS sensors; ${ }^{43}$ (2) noise removal from weekly NDVI and BT, which includes development of weekly composite NDVI and BT from their daily data, removing low (weekly) frequency noise, due to clouds, aerosols, elevated moisture, etc. from annual indices' time series; removing high frequency noise (difference among the sensors, heavy aerosols from volcanoes, late equator crossing time, and others) from the indices; and approximation of their annual cycle; and (3) calculation of VHI from the noise-reduced NDVI and BT to characterize satellite-based weather component (WC). ${ }^{9,10,34}$

The last step is theoretically grounded since NDVI and BT quantify two environmental components (a) spatial difference between productivity of ecosystems and (b) weather-related variations in each ecosystem. The problem is that the first one is controlled by long-term environmental factors such as climate, soils, topography, landscape, etc., which further will be called ecosystem component (EC), and the second is controlled by short-term WC. From the two components (EC and WC), short-term weather-related NDVI and BT variations control annual crop productivity. Because the WC is much smaller than the EC, the EC was removed from NDVI and BT. ${ }^{9,34}$ Following these considerations, first, multiyear climatology of NDVI and BT was calculated based on three environmental laws: Leibig's law-of-minimum, Shelford's law-of-tolerance and principle of carrying capacity), and second, annual fluctuations of NDVI and BT from their climatology were approximated. As a result, NDVI-based vegetation condition index (VCI), BT-based temperature condition index (TCI), and VCI-TCI combined VHI were approximated as

$$
\begin{gathered}
\mathrm{VCI}=100 *\left(\mathrm{NDVI}-\mathrm{NDVI}_{\min }\right) /\left(\mathrm{NDVI}_{\max }-\mathrm{NDVI}_{\min }\right), \\
\mathrm{TCI}=100 *\left(\mathrm{BT}_{\max }-\mathrm{BT}\right) /\left(\mathrm{BT}_{\max }-\mathrm{BT}_{\min }\right), \\
\mathrm{VHI}=a * \mathrm{VCI}+(1-a) * \mathrm{TCI} .
\end{gathered}
$$

NDVI, NDVI $I_{\max }$, and $\mathrm{NDVI}_{\min }\left(\mathrm{BT}, \mathrm{BT}_{\max }\right.$, and $\left.\mathrm{BT}_{\text {tmin }}\right)$ are no noise weekly NDVI and $\mathrm{BT}$ and their 1981 to 2016 absolute maximum and minimum (climatology), respectively; $a$ is a coefficient quantifying a share of VCI and TCI contribution in the VHI. Since this share is generally not known for specific crop and location, it was assumed that VCI and TCI contributions are equal $(a=0.5)$.

The VCI, TCI, and VHI have numeric values varying from 0 to 100 where zero estimates exceptional vegetation stress, 100 and 50 estimate favorable and near-normal conditions, 
respectively. Area-average VCI, TCI, and VHI were calculated for the major growing area of wheat shown in Fig. 1(d). Application of these indices in some countries showed that they correlate strongly with productivity of crops and pastures and can be used as satellite-based numerical weather-related indicators of crop yield in advance of harvest. ${ }^{12,13,31-35}$ Further discussion is focused on the indices applied to Australia wheat.

\section{Correlation and Regression Analysis}

According to the modeling methodology, $d Y$-VH (VCI, TCI, and VHI) correlation analysis was performed. Since Australia is the Southern Hemisphere country the wheat is growing in their winter. It is planted in May-June (sometimes as late as in early July) and harvested in NovemberDecember. There are several varieties of wheat $(\mathrm{w})$ : prime hard $\mathrm{w}$, hard $\mathrm{w}$, premium white $\mathrm{w}$, noodle w, durum, and GPW. The GPW area is the largest and equivalent to hard wheat. ${ }^{39}$ Figure 3 shows correlation dynamics of $\mathrm{d} Y$ versus the indices during Australia's wheat year (January through December). Our interests were to investigate (a) the strength of $d Y$-VCI, $d Y$-TCI, and $d Y$-VHI relationship, using Pearson correlation coefficients $(R)$ and (b) if the strongest correlation $(R \geq 0.7)$ coincides with wheat's critical period ( $\sim 2$ to 3 weeks before and after heading). The analysis of Fig. 4 indicates that in an early period of wheat season, which is January to April, the correlation for all three VHI is low ( $R=0.2$ to 0.3$)$. It increases sharply during the emergence and green biomass accumulation (after May to June), reaching maximum at weeks 38 to 40 , September to October. Thermal conditions ( $\mathrm{d} Y$ correlation with $\mathrm{TCI}$ ) are as important as moisture $(\mathrm{d} Y-\mathrm{VCI})$ and moisture-thermal combination $(\mathrm{d} Y-\mathrm{VHI})$. The importance of thermal conditions starts 2 weeks later compared to moisture. The maximum $\mathrm{d} Y$ correlation with TCI in Fig. 4 comes to the weeks 40 to 41, which coincides with the critical period of wheat development (around heading and flowering). During this period, good water supply and cooler temperatures stimulate larger wheat yield. Following the figure, a positive correlation between $\mathrm{d} Y$ and VHI indicates that when yield is below trend, VHI have values below 40 indicating moisture stress (lack of water) and thermal stress (hotter weather). Oppositely, above trend yield occurs when VHI are above 60 (favorable conditions, when weather is wet and cool). After September to October the $\mathrm{d} Y-\mathrm{VH}$ correlation is gradually declining.

$$
\begin{aligned}
\mathrm{d} Y= & -1.061+0.0036 * \mathrm{VCI}_{36}+0.0036 * \mathrm{VCI}_{37}+0.0039 * \mathrm{VCI}_{38}+0.0039 * \mathrm{VCI}_{39} \\
& +0.0038 * \mathrm{VCI}_{40} \mathrm{RM}=0.799 ; \quad \mathrm{StDev}=0.242 ; \\
\mathrm{d} Y= & -0.726+0.0029 * \mathrm{TCI}_{38}+0.003 * \mathrm{TCI}_{39}+0.003 * \mathrm{TCI}_{40}+0.003 * \mathrm{TCI}_{41}+0.003 \\
& * \mathrm{TCI}_{42} \mathrm{RM}=0.684 ; \quad \mathrm{StDev}=0.300 ; \\
\mathrm{d} Y= & -0.982+0.0035 * \mathrm{VHI}_{36}+0.0038 * \mathrm{VHI}_{37}+0.0038 * \mathrm{VHI}_{38}+0.0038 * \mathrm{VHI}_{39} \\
& +0.0038 * \mathrm{VHI}_{40} \mathrm{RM}=0.777 ; \quad \mathrm{StDev}=0.276 ; \\
& \mathrm{d} Y=-1.115+0.0168 * \mathrm{VCI}_{38}+0.0144 * \mathrm{TCI}_{40} ; \quad \mathrm{R}=0.785 ; \quad \mathrm{RM}=0.801 \\
\mathrm{StDev}= & 0.239 .
\end{aligned}
$$
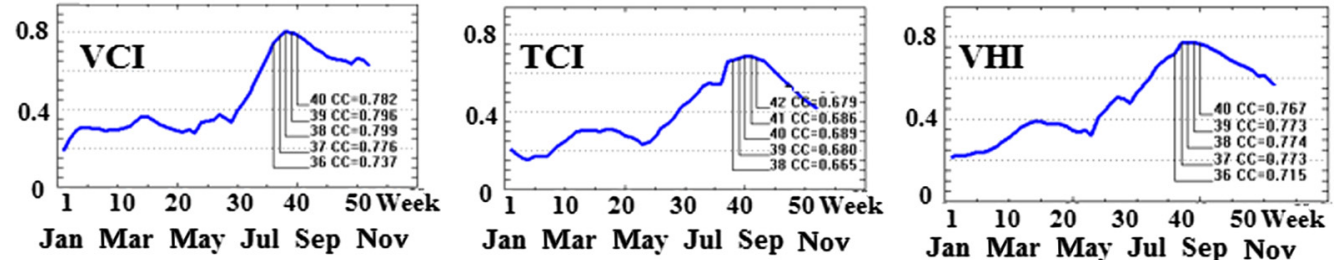

Fig. 4 Correlation time series between annual hard wheat $\mathrm{d} Y$ and weekly $\mathrm{VCl}, \mathrm{TCl}$, and $\mathrm{VHI}$ in Australia's hard wheat area. 

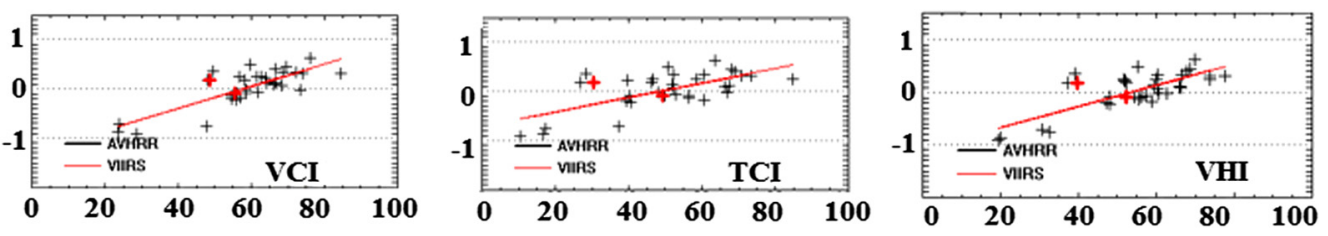

Fig. 5 Scatter plots of hard wheat $\mathrm{d} Y$ versus weekly indices ( $\mathrm{VCl}, \mathrm{TCl}, \mathrm{VHI}$, and $\mathrm{VCl}-\mathrm{TCl})$, when several weeks during crop's critical period in Australia were combined together [Eqs. (10)-(13)].

Finally, regression Eqs. (6)-(8) have been developed relating $\mathrm{d} Y$ with each index for the most correlated weeks. All three have high multiple correlation coefficient (RM). Moisture conditions (VCI) having higher correlation are the most important and thermal conditions are slightly less (the lowest RM). Meanwhile, their combination (VHI) has a high correlation and a very good predictive power. At the same time, it is important to mention that following regression coefficient values contribution of different weeks' indices into final model prediction is almost equal. Therefore, additional model was developed with two variables only VCI and TCI for the weeks of their highest correlation [Eq. (9)]. The statistical estimate of the Eq. (9) shows that its performance is similar ( $\mathrm{RM}=0.785$ and $\mathrm{StDev}=0.256)$ to $\mathrm{d} Y$-VCI [Eq. (6)] and $\mathrm{d} Y$-VHI Eq. (8).

Equations (6)-(8) analysis indicates that the contribution of indices of the neighboring weeks are practically equal. Moreover, the neighboring weeks indices are collinear, which might lead to some errors when models are applied for yield prediction. Therefore, for each index (VCI, TCI, and VHI), weekly variables with the highest Pearson correlation coefficient (PCC) were combined together with the weights corresponding to the value of the $\mathrm{d} Y$-VH PCC for the corresponding weeks. Following these considerations, four models were developed

$$
\begin{aligned}
\mathrm{d} Y & =-1.063+0.0189 * \mathrm{VCI}_{36-40} \mathrm{RM}=0.776 \\
\mathrm{VCI}_{36-40} & =0.189 * \mathrm{VCI}_{36}+0.199 * \mathrm{VCI}_{37}+0.205 * \mathrm{VCI}_{38}+0.205 * \mathrm{VCI}_{39}+0.201 * \mathrm{VCI}_{40} ;
\end{aligned}
$$

$$
\begin{aligned}
\mathrm{d} Y & =-0.726+0.0148 * \mathrm{TCI}_{38-42} \mathrm{RM}=0.684 \\
\mathrm{TCI}_{38-42} & =0.196 * \mathrm{TCI}_{38}+0.200 * \mathrm{TCI}_{39}+0.203 * \mathrm{TCI}_{40}+0.202 * \mathrm{TCI}_{41}+0.200 * \mathrm{TCI}_{42}
\end{aligned}
$$

$$
\begin{aligned}
\mathrm{d} Y & =-0.982+0.0186 * \mathrm{VHI}_{36-40} \mathrm{RM}=0.777 \\
\mathrm{VHI}_{36-40} & =0.196 * \mathrm{VHI}_{36}+0.200 * \mathrm{VHI}_{37}+0.203 * \mathrm{VHI}_{38}+0.202 * \mathrm{VHI}_{39}+0.200 * \mathrm{VHI}_{40} ;
\end{aligned}
$$

$$
\begin{aligned}
\mathrm{d} Y & =1.175+0.0206 * \mathrm{VCI}_{38} \mathrm{TCI}_{42} \mathrm{RM}=0.755 \\
\mathrm{VCI}_{38} \mathrm{TCI}_{42} & =0.54 * \mathrm{VCI}_{38}+0.46 * \mathrm{TCI}_{42} .
\end{aligned}
$$

Statistical assessments of these models' performance do not show many differences with the previous models [Eqs. (6)-(9)]. Figure 5 demonstrates Pearson correlation $(R)$ between $\mathrm{d} Y$ and the multiweek blended VHI. The correlation for most of the indices is strong $(R \geq 0.7)$. However, it is mostly similar to the previous four models [Eqs. (6)-(9)].

\section{Independent Model Testing}

One of the most important procedure with $\mathrm{d} Y-\mathrm{VH}$ modeling is model validation. Therefore, the last four models [Eqs. (10)-(13)] were tested independently for the accuracy of predictions. Considering a relatively short period of the investigated data, the "Jacknife" (or "one-out, one-in") technique was used for independent model testing. Following this technique, years 
Table 1 Statistics of Eqs. (10)-(13).

\begin{tabular}{lccc}
\hline \hline Model \# & $R$ & StDev & Mean difference \\
\hline Model (10) & 0.804 & 0.242 & 0.0028 \\
Model (11) & 0.683 & 0.300 & 0.0045 \\
Model (12) & 0.737 & 0.276 & 0.0033 \\
Model (13) & 0.785 & 0.256 & 0.0018 \\
\hline \hline
\end{tabular}

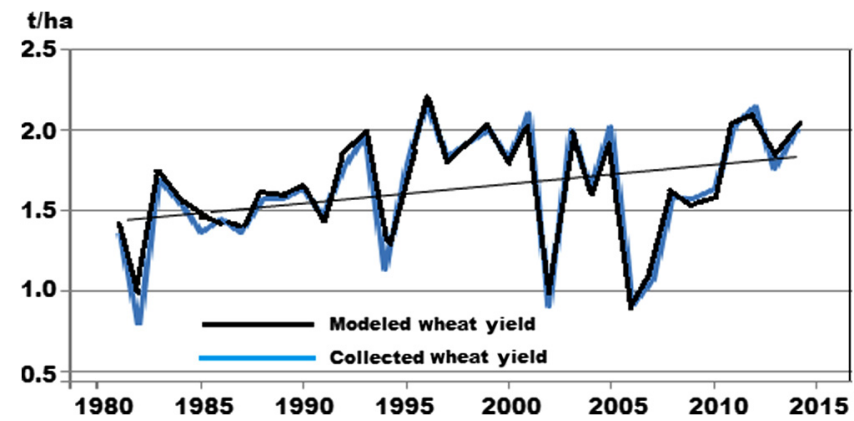

Fig. 6 Australia's hard wheat yields during 1981 to 2014: collected and predicted by Eq. (13) model.

were removed one-by-one from the data set, a new equation was developed (without the eliminated year's data) and this equation was applied to predict $\mathrm{d} Y$ of the eliminated year. This procedure was performed 33 times and $\mathrm{dY}$ was calculated for each year not included in model's development [Eqs. (10)-(13)]. Finally, Eq. (7) was used to calculate simulated (predicted) wheat yield $(Y)$ based on independently $\mathrm{VH}$-simulated $\mathrm{d} Y$ and approximate $Y t$ [Eq. (6)]. Finally, the independently predicted (PY) and measured (MY) wheat yield were statistically evaluated (Table 1) and showed fairly good independent performance.

Figure 6 shows time series of hard wheat's actual yield (blue line) versus independently evaluated (using "Jacknife" approach) yield (black line) from model Eq. (13) when both moisture (VCI) and thermal (TCI) indices were used as predictors. Coincidence between the independently evaluated model's yield prediction and the collected wheat yield is very decent, especially good coincidence for extreme yield fluctuations. Since the prediction is provided in mid-October, which is 1 month ahead of harvest, there is some lead time for development of an advanced marketing strategy.

\section{Conclusions}

This globally universal satellite-based VH technique for monitoring VH, including drought detection and impact assessment, was used to model wheat yield in the principal growing areas of Australia. Correlation and regression analysis during 1981 to 2014 showed a strong relationship between wheat yield anomaly (deviation from technological trend) and VCI, TCI, and VHI (weekly weather-related components of the environment) during the period of highest wheat yield sensitivity to weather (critical period). This period starts 2 to 3 weeks before and ends up 2 to 3 weeks after wheat heading. The developed models provide prediction of wheat yield 1 to 2 months in advance of harvest. This paper proved again that the VH methodology can be applied to many different environments. The advance yield prediction in Australia from NOAA operational satellites can help the agricultural community plan in advance wheat delivery to the international market and also help countries address food security issues.

The VHI and historical data are delivered every week to the following NOAA WEB, ${ }^{44}$ which shows 37-year global, continental, country (192), and the first-order administrative regions 
(around 4000) $\mathrm{VH}$, drought (start/end, area, intensity, and origination), moisture and thermal conditions, moisture and thermal crop stress, fire risk potential, and other indicators useful for real-time monitoring and climate services. Nearly 12,000 (depending on the season) users access this WEB site every month. Finally, the VH-based crop monitoring method is currently being improved (providing $1 \mathrm{~km}^{2}$ data) with observations from Suomi NPP (S-NPP), launched in 2011, and will continue this improvement with the November 2017 lunch of NOAA-20, satellite (providing $0.5 \mathrm{~km}^{2}$ data). The new generation of polar-orbiting satellites is scheduled to be in space until the mid-2030s and will considerably improve VH-based assessments (crop and pasture monitoring, drought detection, impacts assessments, and prediction of food security in Africa and Asia).

\section{Disclaimer}

Manuscript content is solely the opinion of the authors and do not constitute a statement of policy, decision or position on behalf of NOAA or U.S. Government.

\section{References}

1. FAO, "Crop production," 2016, Rome, Italy http://fao.org.

2. AG (Australia Government), "Australia's reference climate station network," 2016, http:// www.bom.gov.au/climate/change/reference.shtml.

3. USDA, Economic Research Service, "Trade: world wheat trade," 2016, http://www.ers.usda .gov/topics/crops/wheat/trade/ (26 October 2016).

4. AG (Australia Government), Farm Agriculture and Food, 2017, http://www.agriculture.gov. au/ag-farm-food/crops/wheat.

5. I. A. Gol'tsberg, Ed., Agroclimaticheskii Atlas Mira (Agroclimatic Atlas of the World), p. 145, Gidrometizdat, Moscow-Lemingrad (1972).

6. VH, "Vegetation health product and data," 2017, https://www.star.nesdis.noaa.gov/smcd/ emb/vci/VH/vh_browse.php.

7. D. Jakob and D. Walland, "Variability and long-term change in Australian temperature and precipitation extremes," Weather Clim. Extremes 14, 36-55 (2016).

8. K. B. Kidwell, "Global vegetation index user's guide," NOAA Technical Report, p. 65, Department of Commerce, Washington D.C. (1997).

9. F. N. Kogan, "Vegetation health index for areal analysis of NDVI in monitoring crop conditions," in Preprint 18th Conf. on Agricultural and Forest Meteorology, pp. 103-114, AMS, Boston (1987).

10. F. N. Kogan, "Operational space technology for global vegetation assessment," Bull. Am. Meteorol. Soc. 82(9), 1949-1964 (2001).

11. NOAA, "Visible infrared imaging radiometer suite (VIIRS) sensor data record (SDR) user's guide version 1.2," NOAA Technical Report NESDIS 142A, p. 43, Washington, DC (2013).

12. F. Kogan et al., "Winter wheat yield forecasting in Ukraine based on earth observation, meteorological data and biophysical models," Int. J. Appl. Earth Obs. Geoinf. 23(2013), 192-203 (2013).

13. F. N. Kogan, B. Yang, and G. Wei, "Modeling corn yield in China using AVHRR-based vegetation health indices," Int. J. Remote Sens. 26(11), 2325-2336 (2005).

14. S. B. Idso et al., "Estimation of grain yields by remote sensing of crop senescence rates," Remote Sens. Environ. 9, 87-91 (1980).

15. T. L. Barnett and D. R. Thompson, "Large-area relation of Landsat MSS and NOAA-6 AVHRR spectral data to wheat yields," Remote Sens. Environ. 13, 277-290 (1983).

16. J. W. Rouse et al., "Monitoring vegetation systems in the Great Plains with ERTS," in Proc. of the third ERTS Symp., pp. 309-317 (1973).

17. C. J. Tucker et al., "Satellite remote sensing of total dry matter production in the Senegalese Sahel," Remote Sens. Environ. 13, 461-474 (1983).

18. G. E. Johnson, A. van Dijk, and C. M. Sakamoto, "The use of AVHRR data in operational agricultural assessment in Africa," Geocarto Int. 2, 41-60 (1987). 
19. S. N. Goward and D. G. Dye, "Evaluating North American net primary productivity with satellite observations," Adv. Space Res. 7, 165-174 (1987).

20. M. S. Rasmussen, "Assessment of millet yields and production in northern Burkina Faso using integrated NDVI from the AVHRR," Int. J. Remote Sens. 13, 3431-3442 (1992).

21. S. M. E. Groten, "NDVI-crop monitoring and early yield assessment of Burkina Faso," Int. J. Remote Sens. 14, 1495-1515 (1993).

22. F. Maselli and F. Rembold, "Analysis of GAC NDVI data for cropland identification and yield forecasting in Mediterranean African countries," Photogramm. Eng. Remote Sens. 67, 593-602 (2001).

23. FS, "Food security and nutrition analysis 2012/13," Technical Series Report No VI. 50, p. 174, Nairobi, Kenya (2013).

24. M. J. Hayes and W. L. Decker, "Using NOAA AVHRR data to estimate maize production in the United States Corn Belt," Int. J. Remote Sens. 17, 3189-3200 (1996).

25. N. A. Noureldin et al., "Rice yield forecasting models using satellite imagery in Egypt," Egypt. J. Remote Sens. Space Sci. 16(1), 125-131 (2013).

26. A. P. Cracknell, The Advanced Very High Resolution Radiometer, p. 534, Taylor \& Francis, Bristol, Pennsylvania (1997).

27. ABM (Australian Bureau of Meteorology), "ABM land surface data," 2018, http://www. bom.gov.au/climate/change/\#tabs=Tracker\&tracker=timeseries.

28. ABS (Australian Bureau of Statistics), "Agricultural census data for 2010-2011," 2012, http://www.abs.gov.au/.

29. IPCC, "Climate change 2014," Synthesis Report, 5th Assessment, R. K. Pachauri and L. Meyer, Eds., p. 151, Geneva, Switzerland (2014), https://www.ipcc.ch/pdf/assessmentreport/ar5/syr/SYR_AR5_FINAL_full_wcover.pdf.

30. A. D. Báez-González et al., "Using satellite and field data with crop growth modeling to monitor and estimate corn yield in Mexico," Crop Sci. 42(6), 1943-1949 (2001).

31. F. Kogan et al., "Modelling and prediction of crop losses from NOAA polar-orbiting operational satellites," Geomatics Nat. Hazards Risk 7, 886-900 (2015).

32. F. Kogan, L. Salazar, and L. Roytman, "Forecasting crop production using satellite based vegetation health indices in Kansas, United States," Int. J. Remote Sens. 33(9), 2798-2814 (2012).

33. L. Salazar, F. Kogan, and L. Roytman, "Use of remote sensing data for estimation of winter wheat yield in the United States," Int. J. Remote Sens. 28(17-18), 3795-3811 (2007).

34. F. Kogan et al., "AVHRR-based spectral vegetation indices for quantitative assessment of vegetation state and productivity: calibration and validation," Photogramm. Remote Sens. 69, 899-906 (2003).

35. L. S. Unganai and F. N. Kogan, "Drought monitoring and corn yield estimation in Southern Africa from AVHRR data," Remote Sens. Environ. 63, 219-232 (1998).

36. W. T. Liu and F. Kogan, "Monitoring Brazilian soybean production using NOAA/AVHRR based vegetation condition indices," Int. J. Remote Sens. 23, 1161-1179 (2002).

37. K. Dabrowska-Zielinska et al., "Modeling of crop conditions and yield in Poland using AVHRR-based indices," Int. J. Remote Sens. 23, 1109-1123 (2002).

38. C. Domenikiotis et al., "Early cotton yield assessment by the use of the NOAA/AVHRR derived vegetation condition index (VCI) in Greece," Int. J. Remote Sens. 25(14), 28072819 (2004).

39. AWXB, "Australian wheat," 2018, http://www.awb.com.au/customers/australianwheat/.

40. V. M. Obuhov, Urozhainost I Meteorologicheskie Factoru (Yield and Meteorological Factors), p. 315, Gosplanizdat, Moscow (1949).

41. F. Kogan, Impact of Climate and Technology on Soviet Grain Production, p. 178, DELPHIC Inc., Falls Church, Virginia (1986).

42. NOAA/NESDIS, "Global vegetation health indices and their applications" (2018), https:// www.star.nesdis.noaa.gov/smcd/emb/vci/VH/vh_browse.php.

43. F. Kogan, W. Guo, and W. Yang, "SNPP/VIIRS vegetation health to assess 500 California drought," Geomatics Nat. Hazards Risk 8, 1383-1395 (2017).

44. http://www.star.nesdis.noaa.gov/smcd/emb/vci/VH/index.php. 
Felix Kogan is a physical scientist at NOAA/NESDIS, Center for Satellite Application and Research (STAR). He is a developer of satellite-based vegetation health (VH) method and VH applications. His research interests include drought detection and monitoring, VH-yield modeling, fire risk, malaria monitoring, vegetation stress, climate change, VH data distribution, etc. He has authored around 170 publications. He received his MS degree from USSR's Odessa Hydrometeorological Institute and his PhD from USSR's Hydrometeorological Center in Moscow.

Wei Guo is a senior scientific programmer, IMSG at NOAA/NESDIS/STAR. He is a developer of Global Vegetation Health software for data retrieval, processing, and applications, and VH/ WEB for users (data retrieval, display, and applications). He is an internet developer and scientific programmer. He received his MS degree in satellite meteorology, Peking University, China.

Wenze Yang is a research scientist in IMSG. He has 16 years of experience in satellite remote sensing R\&D, Research and Operations. His research interests and specializations include remote sensing vegetation, satellite data development, evaluation, fusion and application, climate-ecosystem interactions, etc. He received his BS and MS degrees in automation engineering from Tsinghua University, China, and $\mathrm{PhD}$ in geography from USA's Boston University.

Harlan Shannon is a meteorologist at the U.S. Department of Agriculture World Agricultural Outlook Board (WAOB). His duties are assessment of weather and climate impacts on Australian agriculture, support WAOB agricultural weather and drought monitoring activities, and serving as the WAOB focal point for World Meteorological Organization (WMO). He is managing a Group of the WMO Commission for Agricultural Meteorology (CAgM), coordinating CAgM efforts to support agrometeorological services worldwide. He graduated (BS, MS, PhD) from USA's Pennsylvania State University. 